\begin{tabular}{|l|l|l|}
\hline Volume 5, Number 10 & Research Question Review & 31 DECEMBER 2021 \\
\hline
\end{tabular}

\title{
How Does Organizational Culture Influence the Adoption of Research Evidence by Management Practitioners?
}

By

Juan Carlos Cruz, Center for Evidence-Based Management

Justin Blaney, University of Washington

U sing the best available evidence from multiple sources can lead to more effective management practice. However, management practitioners often make decisions based on limited evidence, mostly from personal experience and judgment. Organizational culture may conflict with a manager's ability to use research evidence in practice.

This systematic review suggests that an integration of the diffusion of innovations (Rogers, 1995) and planned behavior (Ajzen, 1991) theories may explain the influence of organizational culture on the adoption of research evidence by management practitioners. Specifically, practitioner beliefs, values, and practices within an organization may be conceptualized as moderating the effects of innovation diffusion efforts on research evidence adoption behavior.
Viewing research evidence utilization as an innovation, organizational managers may employ innovation diffusion strategies to influence beliefs, values, and practices conducive to using research evidence in management practice. This review presents recommendations for both practitioners and scholars to facilitate re-
Organizational culture may conflict with practitioner research evidence utilization. This systematic review synthesizes academic literature evidence on how organizational culture influences the adoption of research evidence by management practitioners. search evidence utiliza tion. Practitioners can promote a culture that enables evidence-based practice, use tact when presenting research evidence to a skeptical audience, and form partnerships with scholars. Leaders can promote the use of research evidence in their organizations, provide evidence-based practice tools and training, and use human resource practices to ensure key positions are proficient in research skills. Scholars can publish more practitioner-friendly research evidence and teach business and management students research skills.

Keywords: Change, Diffusion of Innovations, Evidence-based Management, Planned Behavior, Management Practitioners, Organizational Behavior, Organizational Culture, Systematic Review

Copyright ( 2021 , Juan C. Cruz Justin Blaney. This article is published under a Creative Commons BY-NC license. Permission is granted to copy and distribute this article for non-commercial purposes, in both printed and electronic formats 
Using the best evidence available in decision-making has been described as a "moral obligation" (Barends \& Rousseau, 2018, p. 1). Evidence-based management (EBMgt) brings together the best evidence available from multiple sources to inform decision-making with greater rigor and transparency. These evidence sources include professional experience, organizational data, stakeholder perspectives, and scientific research (Barends \& Rousseau, 2018). Relying on multiple sources of evidence reduces risk, produces new insights, and fills knowledge gaps. For example, Tucker (2014, p. 272) demonstrated that companies without an employee wellness program may be losing an estimated $\$ 375$ per employee per year on obesity costs, not to mention the long-term health detriment to employees. Indeed, evidence-based practice (EBP) revolutionized medicine and promises to revolutionize management practice (Barends et al., 2012; Commission on Evidence-Based Policymaking, 2017).

Yet management decisions are too often based on "dangerous half-truths," sometimes costing organizations millions of dollars and even lives (Pfeffer \& Sutton, 2006, p. 24). Many managers continue basing decisions primarily on personal experience and "management lore" (Buckley et al., 2015, p. 68). This research-practice gap stems from various reasons, including lack of practitioner familiarity with academic research, disbelief in science, and resistance to change (Giluk \& Rynes-Weller, 2012).

A criticism of EBMgt is that insufficient empirical evidence exists regarding its implementation and effectiveness for management decision-making (Reay et al., 2009). Scholars have specifically called for more research on how beliefs, values, and practices affect the adoption of research evidence by management practitioners (Potworowski \& Green, 2012; Rousseau \& Gunia, 2016; Speicher-Bocija \& Adams, 2012). This paper fills this literature gap by producing new insights through a systematic review of available academic literature on this topic.

In this review, organizational culture is defined as the beliefs, values, and practices of the organization. We adopted Potworowski and Green's (2012) conceptualization of beliefs, values, and practices. Namely, beliefs are what individuals within the organization think to be true. Values are a specific belief held by individuals or within organizations about the way things should be. Practices are the activities and routines carried out by individuals in performing work for the organization.

\section{Literature Summary}

Theoretical frameworks for the uptake of research evidence derive from different understandings about what constitutes evidence and the lack of a common framework for evidence (Baba \& HakemZadeh, 2012; Kitson et al., 2008). The most common theo-

\section{Protocol}

This is a systematic review of empirical literature using a framework synthesis (Gough et al., 2017). We developed an emergent framework integrating the theories of diffusion of innovations (Rogers, 1995) and planned behavior (Ajzen, 1991). Within this framework we propose that beliefs, values, and practices serve a moderating role in influencing the adoption of research evidence by management practitioners.

To identify sources for this systematic review, 27 databases were searched using a search string focused on the research question. Additional sources were identified through forward and backward bibliographic cross-referencing (references within the articles and sources that cited key studies). We used predefined inclusion and exclusion criteria combined with Barends and Rousseau's (2018) critical appraisal methods to select the studies of greatest relevance and quality. From a total of 268 sources that were identified, 141 were further screened based on relevance, and 56 were assessed for quality. A total of 22 empirical articles were selected for inclusion in this systematic review, of which 21 are from peer-reviewed scholarly journals and one is from an academic conference.

Using the NVivo 12 Plus qualitative data analysis tool, we manually coded the articles for fit to the initial theoretical framework constructs. In doing so, we employed matrix coding, cluster analysis, and coding queries to triangulate the findings. The analysis resulted in an emergent theoretical framework with actionable recommendations.

retical frameworks that emerged from this systematic review are the theories of rational choice (March, 1994), diffusion of innovations (Rogers, 1995), and planned behavior (Ajzen, 1991).

Some have considered March's (1994) rational choice theory in explaining the adoption of research evidence (Brown \& Zhang, 2016; Shollo et al., 2015). This framework argues that managers will naturally seek after and use evidence to maximize their own effectiveness. In this case, it makes sense to establish patterns of searching for the best available research evidence, since this is an economical way to improve organizations.

Rogers's (1995) diffusion of innovations theory may also explain research evidence adoption (Speicher-Bocija \& Adams, 2012). This theory posits that innovations are diffused as innovators introduce them to early adopters, who facilitate diffusion to other users. Rogers (1995) proposed that an innovation's adoption depends on its relative advantage to the alternative, compatibility with the organization's values, trialability (ability to try it out temporarily), 
observability (visibility to others), and complexity. Framing research evidence within this theory, innovators and early adopters may leverage these adoption factors to influence practitioner beliefs, values, and practices (Flodgren et al., 2019; Yousefi-Nooraie et al., 2012).

Ajzen's (1991) theory of planned behavior offers a behavioral explanation for practitioner research evidence adoption (Barends et al., 2017; Criado-Perez et al., 2019; Rousseau \& Gunia, 2016). This theory proposes that a person's behavioral intent depends on three factors: (1) their attitude toward the behavior, (2) subjective norms based on how individuals believe they will be perceived by others, and (3) the degree of perceived behavioral control over performing the behavior (Ajzen, 1991). We can consider how attitudes, subjective norms, and perceived behavioral control affect a manager's willingness to use research evidence in practice (Barends et al., 2017).

Although rational choice may explain behavior for simple operational decisions, it discounts the role of human judgment (Shollo et al., 2015). Moreover, human behavior is often irrational, deadlines limit the time available for research, and managers often make decisions with incomplete information (Brown \& Zhang, 2016; HakemZadeh \& Baba, 2016). Such limitations make the rational choice theory less fit for the purpose of explaining research evidence uptake in management practice. On the other hand, Rogers's (1995) innovation diffusion theory and Ajzen's (1991) planned behavior theory are more frequently cited in the literature. Stols and Kriek
(2011) successfully integrated these theories to explain technology adoption in schools. Furthermore, the innovation diffusion (Rogers, 1995) and planned behavior (Ajzen, 1991) theories provide frameworks that are more flexible to human behavior and external factors.

Conceptualizing research evidence utilization as an innovation, we propose integrating Rogers's (1995) and Ajzen's (1991) theories as an initial framework to understand the influence of organizational culture on research evidence adoption (see Figure 1). We characterize the organizational culture factors as a lens which moderates the effect of the innovation diffusion adoption factors (Rogers, 1995) on the planned behavior constructs (Ajzen, 1991). The framework's constructs are defined in Table 1.

During the course of the systematic review, we extracted data from the included studies, which were used for the critical appraisal and to identify initial themes and findings. The data extracted from each study included: authors, publication year, research design, sample size, sector or population, outcome measures, theoretical framework, main findings, possible moderators or mediators, effect sizes, recommendations, and limitations. Table 2 summarizes the findings that were extracted of each of the 22 studies included in this review. Detailed data extraction tables are available upon request. The discussion section that follows summarizes the findings that emerged from the synthesis of the 22 included studies.

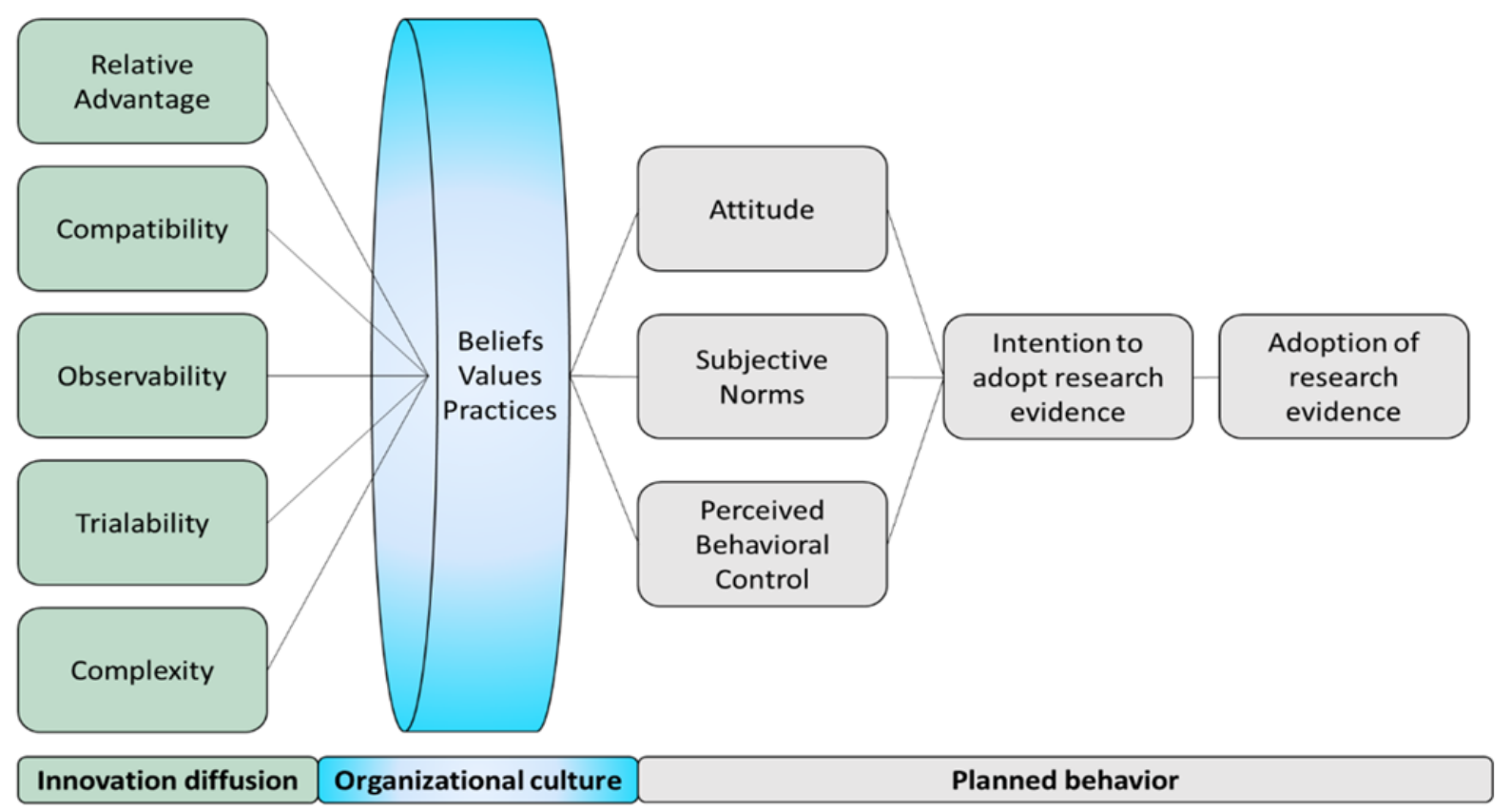

Figure 1: Initial Theoretical Framework

Note. The innovation diffusion factors are from Rogers (1995) and the planned behavior model is from Ajzen (1991). 
Table 1: Definition of Constructs from the Theoretical Framework

\begin{tabular}{|l|l|}
\hline \multicolumn{1}{|c|}{ Construct } & \multicolumn{1}{c|}{ Definition } \\
\hline $\begin{array}{l}\text { Relative advan- } \\
\text { tage }\end{array}$ & $\begin{array}{l}\text { "The degree to which an innovation is perceived as being better than the idea it } \\
\text { supersedes" (Rogers, 1995, p. 213). }\end{array}$ \\
\hline Compatibility & $\begin{array}{l}\text { "The degree to which an innovation is perceived as consistent with the existing } \\
\text { values, past experiences, and needs of potential adopters" (Rogers, 1995, p. 223). }\end{array}$ \\
\hline Observability & $\begin{array}{l}\text { "the degree to which the results of an innovation are visible to others" (Rogers, } \\
\text { 1995, p. 232). }\end{array}$ \\
\hline Trialability & $\begin{array}{l}\text { "the degree to which an innovation may be experimented with on a limited } \\
\text { basis" (Rogers, 1995, p. 231). }\end{array}$ \\
\hline Complexity & $\begin{array}{l}\text { "the degree to which an innovation is perceived as relatively difficult to under- } \\
\text { stand and use" (Rogers, 1995, p. 230). }\end{array}$ \\
\hline Beliefs & $\begin{array}{l}\text { "A truth claim about the past, present, or possible future" (Potworowski \& } \\
\text { Green, 2012, p. 273) }\end{array}$ \\
\hline Values & $\begin{array}{l}\text { “a specific type of belief - one about how things ought to be (or ought to have } \\
\text { been) - given beliefs about how things can possibly be (or could have been)" } \\
\text { (Potworowski \& Green, 2012, p. 273-274) }\end{array}$ \\
\hline Practices & $\begin{array}{l}\text { “The coordinated activities of individuals and groups in doing their 'real work' } \\
\text { as it is informed by a particular organizational or group context" (Cook \& } \\
\text { Brown, 1999, p. 386-387, as cited in Potworowski \& Green, 2012, p. 274) }\end{array}$ \\
\hline Attitude & $\begin{array}{l}\text { "The degree to which a person has a favorable or unfavorable evaluation or } \\
\text { appraisal of the behavior in question" (Ajzen, 1991, p. 188). }\end{array}$ \\
\hline Subjective norms & $\begin{array}{l}\text { “The perceived social pressure to perform or not perform the behavior" (Ajzen, } \\
\text { 1991, p. 188). }\end{array}$ \\
\hline $\begin{array}{l}\text { Perceived behav- } \\
\text { ioral control }\end{array}$ & $\begin{array}{l}\text { "The perceived ease or difficulty of performing the behavior" (Ajzen, 1991, p. } \\
\text { 188). }\end{array}$ \\
\hline
\end{tabular}

Table 2: Findings from Each of the Studies Included in the Synthesis

\begin{tabular}{|l|l|}
\hline \multicolumn{1}{|c|}{ Source } & \multicolumn{1}{c|}{ Findings } \\
\hline $\begin{array}{l}\text { Barends et al., } \\
2017\end{array}$ & $\begin{array}{l}\text { Most managers had positive attitudes toward EBP. However, lack of time and a } \\
\text { limited understanding of scientific research were perceived as major barriers to } \\
\text { using research evidence in management. }\end{array}$ \\
\hline $\begin{array}{l}\text { Bezzina et al., } \\
2017\end{array}$ & $\begin{array}{l}\text { Managers largely believed in HR practices that were not evidence-based. This } \\
\text { belief in non-evidence-based HR practices increased with level of professional } \\
\text { experience. Managers had little awareness of and time to consult academic HR } \\
\text { literature. Managers preferred to obtain HR knowledge from popular sources. }\end{array}$ \\
\hline $\begin{array}{l}\text { Brown \& } \\
\text { Zhang, 2016 }\end{array}$ & $\begin{array}{l}\text { More teachers used EBP than those who believed in it. This indicates that teachers } \\
\text { used EBP due to expected compliance rather than cultural acceptance. }\end{array}$ \\
\hline $\begin{array}{l}\text { Caprar et al., } \\
2016\end{array}$ & $\begin{array}{l}\text { Acceptance of evidence was influenced by self-motivated processes of self-en- } \\
\text { hancement and self-protection. }\end{array}$ \\
\hline $\begin{array}{l}\text { Chan et al., } \\
2017\end{array}$ & $\begin{array}{l}\text { Participants who developed arguments upholding misinformation were less likely } \\
\text { to change their beliefs. Participants more likely to scrutinize and counterargue } \\
\text { misinformation were more likely to change their beliefs. Providing new informa- } \\
\text { tion to update the misinformation resulted in participants more likely to change } \\
\text { their beliefs. Providing greater detail in debunking messages did not change mis- } \\
\text { information persistence. }\end{array}$ \\
\hline
\end{tabular}




\begin{tabular}{|c|c|}
\hline Source & Findings \\
\hline $\begin{array}{l}\text { Criado-Perez et } \\
\text { al., } 2019\end{array}$ & $\begin{array}{l}\text { Managers trusted personal experience, organizational knowledge, and consultant } \\
\text { advice in decision-making, but scientific research was largely neglected. Managers } \\
\text { focused more on practice-based knowledge and interpreted evidence more flexibly, } \\
\text { often for the purpose of justifying decisions, rather than guiding decisions. Learn- } \\
\text { ing goal orientation and cultural norms fostered research evidence utilization, } \\
\text { but adoption was also hindered by established routines that reinforce experiential } \\
\text { evidence. }\end{array}$ \\
\hline $\begin{array}{l}\text { Dalheim et al., } \\
2012\end{array}$ & $\begin{array}{l}\text { Nurses largely used evidence from personal experience, colleagues, and other sub- } \\
\text { ject-matter experts in practice, but scientific research was largely neglected. Major } \\
\text { barriers were insufficient time and skills to find and manage research evidence. } \\
\text { Research skills appeared to reduce these barriers and increase research evidence } \\
\text { uptake. }\end{array}$ \\
\hline $\begin{array}{l}\text { Flodgren et al., } \\
2019\end{array}$ & $\begin{array}{l}\text { Opinion leaders influenced EBP uptake, but their effect was weakened by nu- } \\
\text { merous factors. Local opinion leaders being included in an intervention had the } \\
\text { greatest effect on compliance. }\end{array}$ \\
\hline $\begin{array}{l}\text { Francis-Smythe } \\
\text { et al., } 2013\end{array}$ & $\begin{array}{l}\text { Managers primarily turned to their own personal experience and that of col- } \\
\text { leagues for decision-making, largely ignoring the use of research evidence. Man- } \\
\text { agers participating in an MBA program tended to use research evidence less than } \\
\text { those not participating in an MBA program. }\end{array}$ \\
\hline $\begin{array}{l}\text { Glaub et al., } \\
2014\end{array}$ & $\begin{array}{l}\text { Making research evidence actionable improved its use and led to better outcomes } \\
\text { for practitioners. This was exemplified through a randomized controlled trial of } \\
\text { action principles on personal initiative which led to better entrepreneurship out- } \\
\text { comes. }\end{array}$ \\
\hline $\begin{array}{l}\text { Gray et al., } \\
2013\end{array}$ & $\begin{array}{l}\text { Barriers to research evidence utilization included inadequate resources (time, } \\
\text { research access, funding), insufficient skills \& knowledge of practitioners, orga- } \\
\text { nizational culture, research relevance to practice, negative or indifferent attitudes } \\
\text { toward research evidence, and inadequate supervision in research evidence utiliza- } \\
\text { tion. }\end{array}$ \\
\hline $\begin{array}{l}\text { HakemZadeh \& } \\
\text { Baba, } 2016\end{array}$ & $\begin{array}{l}\text { Factors that influenced evidence actionability included operationality, contextual- } \\
\text { ity, comprehensiveness, persuasiveness (rigor and unbiasedness), and comprehen- } \\
\text { sibility. }\end{array}$ \\
\hline $\begin{array}{l}\text { Jacobs et al., } \\
2012\end{array}$ & $\begin{array}{l}\text { Major barriers to evidence-based decision-making were communication of evi- } \\
\text { dence to policymakers, data analysis use, and translation of research to practice. }\end{array}$ \\
\hline $\begin{array}{l}\text { Jepsen \& Rous- } \\
\text { seau, } 2019\end{array}$ & $\begin{array}{l}\text { Employees' perceptions of research evidence use by their managers positively cor- } \\
\text { related with leader-member exchange, trust in manager, and work-based learning. } \\
\text { Perceived research evidence utilization also had a positive effect on perceived orga- } \\
\text { nizational performance. }\end{array}$ \\
\hline Kalyal, 2019 & $\begin{array}{l}\text { Internal environmental factors that influenced receptivity to evidence utilization } \\
\text { included the absorptive capacity of converting research to practice, organization- } \\
\text { al culture and climate, and leadership support. External environmental factors } \\
\text { included monitoring \& review for accountability, funding, and direct \& indirect } \\
\text { networking. }\end{array}$ \\
\hline $\begin{array}{l}\text { McCaughan et } \\
\text { al., } 2002\end{array}$ & $\begin{array}{l}\text { Major barriers to using research evidence in practice included interpreting and } \\
\text { using complex scientific evidence, insufficient organizational support for the use } \\
\text { of research evidence, lack of practitioner actionability in research evidence, lack of } \\
\text { skills and motivation to use research evidence. }\end{array}$ \\
\hline $\begin{array}{l}\text { Murphy et al., } \\
2018\end{array}$ & $\begin{array}{l}\text { Learning research skills in a non-research-focused university course was associat- } \\
\text { ed with higher levels of confidence and attitudes in using research evidence than } \\
\text { learning research skills in research-focused courses alone. Exposure to research } \\
\text { articles increased confidence in using research evidence, especially when exposure } \\
\text { occurred in practice-based learning. }\end{array}$ \\
\hline
\end{tabular}




\begin{tabular}{|l|l|}
\hline \multicolumn{1}{|c|}{ Source } & \multicolumn{1}{c|}{ Findings } \\
\hline $\begin{array}{l}\text { Rynes et al., } \\
2002\end{array}$ & $\begin{array}{l}\text { Large discrepancies were identified between HR practitioner beliefs and research } \\
\text { evidence. HR managers were generally not aware of academic research. HR } \\
\text { managers preferred to turn to industry journals and popular sources for informa- } \\
\text { tion, which often contradicted research evidence. Academic research often lacked } \\
\text { relevance for practitioners. Managers with higher job levels, professional certifi- } \\
\text { cations, and who read academic literature had beliefs more aligned with research } \\
\text { evidence. }\end{array}$ \\
\hline $\begin{array}{l}\text { Shollo et al., } \\
2015\end{array}$ & $\begin{array}{l}\text { Making decisions from a purely rational choice perspective focused on data was } \\
\text { insufficient in situations of ambiguity. In these cases, managers supplemented, } \\
\text { substituted, interpreted, or reframed the evidence through judgment devices of } \\
\text { heuristics, experts, networks, and sponsors. }\end{array}$ \\
\hline $\begin{array}{l}\text { Sosnowy et al., } \\
2013\end{array}$ & $\begin{array}{l}\text { Organizational capacity, resources, and programming were barriers to research } \\
\text { evidence utilization, despite leader interest in EBP. }\end{array}$ \\
\hline $\begin{array}{l}\text { Tenhiala et al., } \\
2016\end{array}$ & $\begin{array}{l}\text { Large discrepancies were identified between HR practitioner beliefs and research } \\
\text { evidence. Interpersonal aspects of managers were more dependent on culture than } \\
\text { technical aspects. While practitioner attitudes of academics were positive, practi- } \\
\text { tioners were not likely to turn to academics or academic literature to resolve HR } \\
\text { problems. }\end{array}$ \\
\hline $\begin{array}{l}\text { Yousefi-Noo- } \\
\text { raie et al., 2012 }\end{array}$ & $\begin{array}{l}\text { When turning to others for evidence, practitioners primarily turned to peers with- } \\
\text { in their own division, and friends or known experts in other divisions. }\end{array}$ \\
\hline
\end{tabular}

\section{Discussion}

The research question sought to identify how organizational culture influences the adoption of research evidence by management practitioners. The coding analysis suggests the organizational culture factors (beliefs, values, and practices) moderated the effects of the innovation diffusion factors (i.e., compatibility, complexity, observability, relative advantage, trialability) on the planned behavior factors (i.e., attitude, behavior control, subjective norms) for practitioner research evidence adoption. During the coding analysis, leader support emerged as an additional construct influencing planned behavior. Thus, leader support was added alongside the innovation diffusion components.

Using NVivo 12 Plus, we manually coded the selected articles for fit within the initial framework. Applying NVivo's matrix coding tool, we measured the number of similarly-coded items between the innovation diffusion and the organizational culture factors, as well as between the organizational culture and planned behavior factors.

To add rigor, we triangulated the matrix coding findings with cluster analyses for word similarity between coded items using Jaccard's index, which measures similarity among documents (Tan et al., 2005, p. 498). Confidence intervals cannot be set on similarity indices because they do not have statistical probability distributions (Krebs, 2014, pp. 524525). Furthermore, we could not measure sample errors due to the limited number of empirical stud- ies found. However, to further support the internal validity of the coding process, we conducted a threeway coding query in NVivo, which identified items coded in combination between the innovation, cultural, and behavioral levels of the framework. The three analyses largely aligned with each other, suggesting relationships between the innovation, cultural, and behavioral factors.

A subjective analysis of the matrix coding, cluster analysis, and the content of coded items determined the measures that constituted strong, moderate, and minor relationships. Thus, while this analysis does not indicate definitive results, we observed that the alignment between matrix coding and cluster analysis became weaker as the number of coinciding references decreased. This suggests that relationships between constructs with a greater number of coding concurrences are more likely to correlate than those with a smaller number of coding concurrences. Nevertheless, the three-way coding query results appeared to positively correlate with the relationship strengths suggested by the matrix coding and cluster analysis results, supporting the internal validity of the relationship strength measures used.

We conceptualized the relationships of the varying levels of evidence between the constructs through an emergent theoretical framework presented in Figure 2. (Detailed coding data tables are available upon request.) We now illustrate specific findings and examples from the strongest evidence found on the influences of beliefs, values, and practices. 


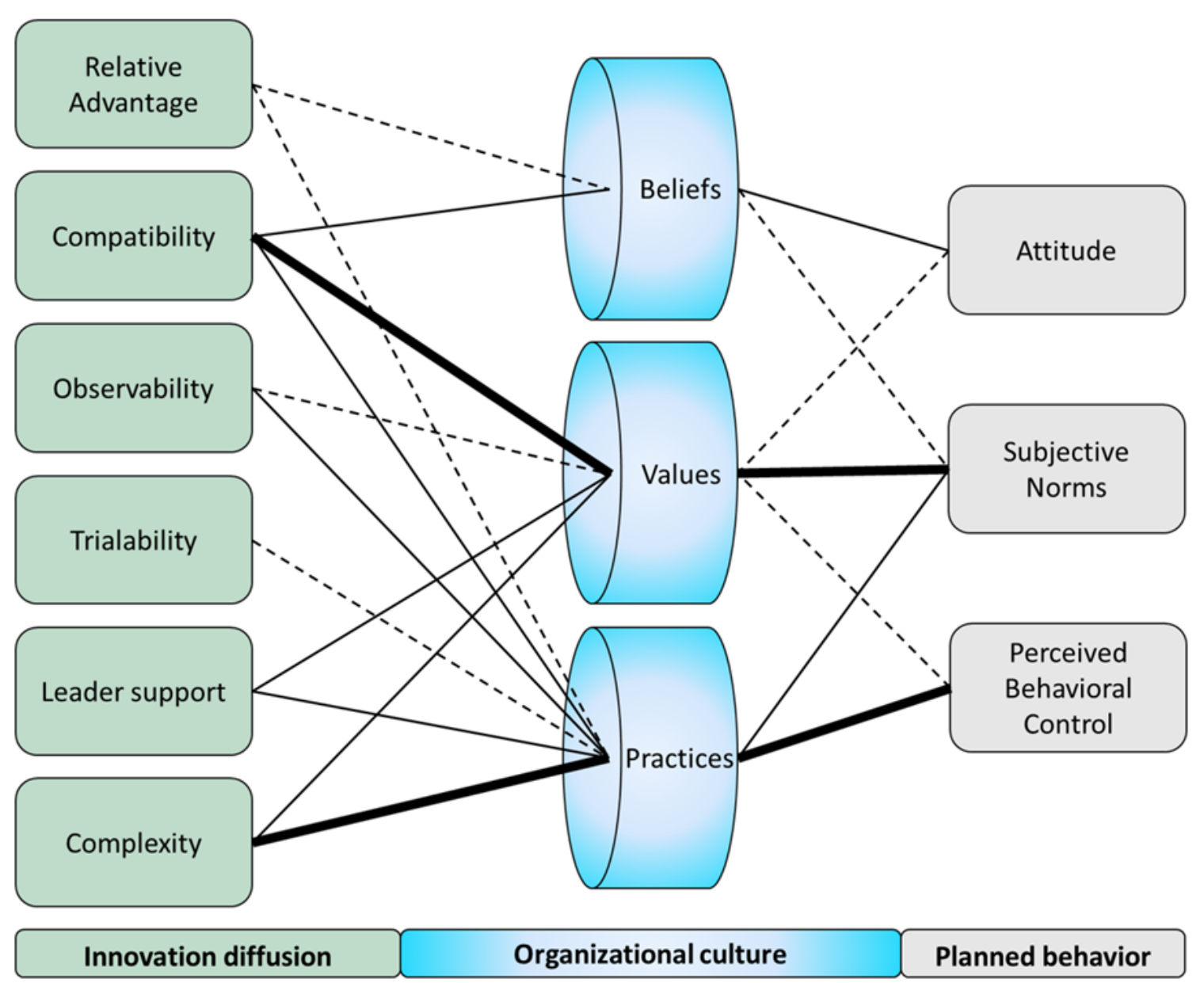

Figure 2: Emergent Theoretical Framework

Note. Thick black lines represent relationships with strong evidence, thin lines have moderate evidence, and dotted lines have minor evidence. The innovation diffusion factors are adapted from Rogers (1995) and the planned behavior factors are from Ajzen (1991)

\section{Practices}

The largest amount of evidence in this review supported the role of management practices in influencing practitioner research evidence uptake. Practices moderated all innovation diffusion factors (plus leader support). Furthermore, practices influenced perceived behavioral control and subjective norms.

The relationship between complexity, practices, and perceived behavioral control had the greatest amount of evidence. The complex nature of scientific research and its accessibility makes it difficult for practitioners to understand and use scientific research (Gray et al., 2013). This complexity can be a burden even in the best circumstances. For example, practitioners with favorable views of and familiarity with research evidence utilization in New York's state health department had difficulty using research in practice due to inadequate access to research and training support (Sosnowy et al., 2013). The most commonly cited complexity barriers were limited time to search for and review research evidence, lack of access to pay-based databases, and a limited understanding of science and academic literature (Barends et al., 2017; Dalheim et al., 2012; McCaughan et al., 2002).

Organizations reduced these complexity barriers by facilitating resources and providing training on using research evidence. For example, some organizations invested in research database subscriptions or accessed them through partnerships with universities and research institutions (Barends et al., 2017; Gray et al., 2013). Providing research skills training to practitioners, especially in practice-based settings and on supervising research evidence utilization, also softened complexity-related barriers (Dalheim et al., 2012; Gray et al., 2013; Murphy et al., 2018). Jacobs et al. (2012) recommended following up training with on-going technical support. However, evidence indicated that many practitioners were not comfortable with conducting research themselves but would use research evidence if it were commu- 
nicated in plain language summaries (Barends et al., 2017; McCaughan et al., 2002). In-house research experts, consultants, and scholars provided such research evidence summaries in different organizations (Bezzina et al., 2017; HakemZadeh \& Baba, 2016; Yousefi-Nooraie et al., 2012).

The influence of compatibility on practices, and its effect on perceived behavioral control and subjective norms had moderate but substantial evidence. Glaub et al. (2014) illustrated these relationships through a randomized controlled trial. In this study, participation in an evidence-based personal initiative training program resulted in improved business outcomes for Ugandan small business owners, compared to those who did not participate in the training program. Relevant and actionable research evidence facilitated operationalization, making it easy for practitioners to adopt research evidence recommendations as part of their routine practice. Feedback from the trainer, oneself, and peers facilitated a culture of accountability in which evidence-based behaviors were positively reinforced by others (Glaub et al., 2014).

Other studies found that organizations that routinely operationalized evidence, supported by peers and leaders, encouraged practitioner use of research evidence (Barends et al., 2017; Dalheim et al., 2012). Such support was particularly important because, after personal experience, the most common source of evidence for manager decision-making was the expertise of others (Francis-Smythe et al., 2013).

The evidence in this review also suggests that leader support and observability strengthened the effect of practices on perceived behavioral control. For example, leaders perceived as using research evidence were able to facilitate and normalize practitioner research evidence use (Jepsen \& Rousseau, 2019). A systematic review demonstrated that opinion leaders successfully promoted the use of research evidence in organizations (Flodgren et al., 2019). Furthermore, a cross-sectional study found that exposure to research evidence, especially during work and practice situations, significantly correlated with practitioner research evidence acceptance (Murphy et al., 2018).

\section{Values}

Evidence from this review demonstrated that values moderated the effect of compatibility, observability, leader support, and complexity on the adoption of research evidence by practitioners. Specifically, there was evidence supporting the influence of values on all three planned behavior constructs.

Strong evidence supported the relationship between compatibility, values, and subjective norms. Decision-making experience and the desire to be busy (resulting in lack of time to review research evidence) were often valued over research evidence utilization and the time required for research activities (Bezzina et al., 2017; Dalheim et al., 2012)However, the compatibility of research evidence with the organization's values often trumped barriers associated with research evidence complexity (Bezzina et al., 2017; Dalheim et al., 2012). Furthermore, without the support of organizational culture and peers, it was difficult for practitioners to use research evidence, even when they were skilled at it (Francis-Smythe et al., 2013; Gray et al., 2013; McCaughan et al., 2002).

For example, a cross-sectional study of primary teachers in England revealed that school administrators could not fully implement EBP through policy because the teachers did not value research evidence as part of their culture and norms (Brown \& Zhang, 2016). The study suggested the administration's efforts could be more successful by promoting the vision of EBP, including modeling and illustrating research evidence utilization, and establishing a learning environment that encourages teachers to discuss research evidence (Brown \& Zhang, 2016). Additionally, interviews of Canadian police executives who used research evidence suggested that open communication, exposure to research evidence, and leadership support can increase openness to research evidence utilization in organizations with strong practice-oriented cultures (Kalyal, 2019). The researcher recommended taking gradual steps in acclimatizing rigid cultures to research evidence utilization, such as offering training and partnering with scholars (Kalyal, 2019).

Values also appeared to moderate the effect of leader support and observability on norms. Leaders were able to successfully promote research evidence use as more compatible with the organization's values and culture when they provided adequate training and support for their organization (Jacobs et al., 2012; McCaughan et al., 2002). Fostering an environment where learning and critical thinking were valued also increased the compatibility of research evidence utilization with organizational values (Criado-Perez et al., 2019; Shollo et al., 2015). Caprar et al. (2016) suggested that cultivating critical thinking ability and learning culture facilitates acceptance of research evidence that challenges individual values.

Leaders influenced organizational values and social norms as they used research evidence themselves in decision-making and held employees accountable for rigor (Jepsen \& Rousseau, 2019; Sosnowy et al., 2013). Greater visibility of leaders using research evidence gave practitioners license to pursue research evidence as part of their workload rather than on top of their workload (Gray et al., 2013; Kalyal, 2019). Research evidence became more observable when practitioners associated with scholars and other practitioners who value research evidence (Kalyal, 2019; Sosnowy et al., 2013). Other ways to increase 
Table 3: Practitioner Recommendations

\begin{tabular}{|c|c|}
\hline Recommendations & Sources \\
\hline $\begin{array}{l}\text { Develop an organizational culture and climate conducive to re- } \\
\text { search evidence use. This includes valuing continuous learning, } \\
\text { critical thinking, and open discussion of research evidence. It } \\
\text { also involves allotting time for research and inquiry. }\end{array}$ & $\begin{array}{l}\text { Caprar et al., 2016; Chan et al., } \\
\text { 2017; Kalyal, 2019; Criado-Perez } \\
\text { et al., 2019; Dalheim et al., 2012; } \\
\text { Francis-Smythe et al., } 2013\end{array}$ \\
\hline $\begin{array}{l}\text { Leaders should promote research evidence utilization. They } \\
\text { should demonstrate that research evidence is important by } \\
\text { considering the best research evidence available in making } \\
\text { their own decisions. They should ensure practitioners have the } \\
\text { resources and support necessary to use research evidence. }\end{array}$ & $\begin{array}{l}\text { Jepsen \& Rousseau, 2019; Jacobs et } \\
\text { al., 2012; McCaughan et al., } 2002\end{array}$ \\
\hline $\begin{array}{l}\text { Make research evidence utilization a routine practice. Provide } \\
\text { regular demonstrations of how research evidence is used, how } \\
\text { it is translated to practice, and how it provides benefits. Offer } \\
\text { opportunities for practitioners to test out using research evi- } \\
\text { dence. }\end{array}$ & $\begin{array}{l}\text { Brown \& Zhang, 2016; Glaub et } \\
\text { al., 2014; Sosnowy et al., 2013; } \\
\text { Kalyal, 2019; Murphy et al., 2018 }\end{array}$ \\
\hline $\begin{array}{l}\text { Use tact in presenting research evidence. Present research evi- } \\
\text { dence dispassionately and encourage the questioning and criti- } \\
\text { cal thinking of evidence, especially when it may be perceived as } \\
\text { threatening to self-concepts, values, and beliefs. Do not simply } \\
\text { label misinformation as incorrect; rather, provide information } \\
\text { to update the misinformation and make efforts to reduce the } \\
\text { perpetuation of arguments supporting misinformation. }\end{array}$ & $\begin{array}{l}\text { Caprar et al., 2016; Chan et al., } \\
\text { 2017; Shollo et al., } 2015\end{array}$ \\
\hline $\begin{array}{l}\text { Use human resource practices to encourage research evidence } \\
\text { utilization. Create positions for research consultants who dis- } \\
\text { seminate plain language evidence summaries. Hire and pro- } \\
\text { mote leaders with a strong learning goal orientation. Provide } \\
\text { student research internship opportunities. }\end{array}$ & $\begin{array}{l}\text { Criado-Perez et al., 2019; Mc- } \\
\text { Caughan et al., 2002; Yousefi-Noo- } \\
\text { raie et al., 2012; Sosnowy et al., } \\
2013\end{array}$ \\
\hline $\begin{array}{l}\text { Provide tools to facilitate research evidence utilization. Access } \\
\text { to research databases and technical support are essential. Struc- } \\
\text { ture and guidelines regarding use of research evidence make } \\
\text { it replicable. Data analytics, logic models, communities of prac- } \\
\text { tice, and other tools can facilitate evidence analysis, translation, } \\
\text { and communication. }\end{array}$ & $\begin{array}{l}\text { Francis-Smythe et al., 2013; Gray } \\
\text { et al., 2013; Kalyal, 2019; Mc- } \\
\text { Caughan et al., 2002; Sosnowy et } \\
\text { al., 2013; Francis-Smythe et al., } \\
\text { 2013; Jacobs et al., 2012; Youse- } \\
\text { fi-Nooraie et al., } 2012\end{array}$ \\
\hline $\begin{array}{l}\text { Provide research skills training and continuous learning } \\
\text { opportunities. The Center for Evidence-Based Management } \\
\text { (n.d.-b) and other institutions and consultants offer training on } \\
\text { research skills and evidence utilization. }\end{array}$ & $\begin{array}{l}\text { (Dalheim et al., 2012; Fran- } \\
\text { cis-Smythe et al., 2013; Sosnowy et } \\
\text { al., } 2013\end{array}$ \\
\hline $\begin{array}{l}\text { Partner with scholars at local universities, through research } \\
\text { institutions, and through social media to promote practi- } \\
\text { tioner-scholar exchange and the actionability of research } \\
\text { findings. }\end{array}$ & $\begin{array}{l}\text { Francis-Smythe et al., 2013; Kaly- } \\
\text { al, 2019; Sosnowy et al., } 2013\end{array}$ \\
\hline
\end{tabular}

practitioner awareness of research evidence included discussing research evidence actionability (Criado-Perez et al., 2019; Francis-Smythe et al., 2013) and employing judgments and labels that make research evidence use attractive (Shollo et al., 2015).

\section{Beliefs}

This review presents evidence that practitioner beliefs moderated the effect of compatibility and relative advantage on attitude and subjective norms.
While less evidence exists for the role of beliefs, the influence of compatibility on attitude, as moderated by beliefs, is noteworthy.

Managers generally had positive perceptions of research evidence and believed it led to more effective decision-making; however, they often had pre-existing beliefs that conflicted with research evidence (Barends et al., 2017; Bezzina et al., 2017). For example, surveys demonstrated that human resources managers worldwide generally lacked awareness 
Table 4: Scholar Recommendations

\begin{tabular}{|l|l|}
\hline \multicolumn{1}{|c|}{ Recommendations } & \multicolumn{1}{c|}{ Sources } \\
\hline $\begin{array}{l}\text { Facilitate scholar-practitioner partnerships, including with indus- } \\
\text { try and professional institutions. }\end{array}$ & $\begin{array}{l}\text { Francis-Smythe et al., 2013; } \\
\text { Kalyal, 2019; Sosnowy et al., } \\
\text { 2013; Rynes et al., 2002 }\end{array}$ \\
\hline $\begin{array}{l}\text { Produce more practitioner-friendly research evidence. Include } \\
\text { plain language summaries in published research. Conduct practi- } \\
\text { tioner-relevant research with actionable findings. Disseminate re- } \\
\text { search evidence through practitioner-friendly media, such as gray } \\
\text { literature, popular magazines, and professional organizations. }\end{array}$ & $\begin{array}{l}\text { Barends et al., 2017; Mc- } \\
\text { Caughan et al., 2002; Bezzina et } \\
\text { al., 2017; HakemZadeh \& Baba, } \\
\text { la et al., 2016 }\end{array}$ \\
\hline $\begin{array}{l}\text { Emphasize teaching research skills to business and management } \\
\text { students. This is particularly important in practice-based courses } \\
\text { to help students connect research with practice. The research skills } \\
\text { taught should include not just how to find evidence, but also how } \\
\text { to appraise evidence quality and how to translate it for practice. }\end{array}$ & $\begin{array}{l}\text { Barends et al., 2017; Fran- } \\
\text { cis-Smythe et al., 2013; Murphy } \\
\text { et al., 2018 }\end{array}$ \\
\hline
\end{tabular}

of scientific research and believed in management practices that diverged from research evidence (Rynes et al., 2002; Tenhiala et al., 2016). Scholars could narrow this divide between research and practitioner perceptions by distributing research evidence through practitioner-friendly publications such as popular and gray literature, and by engaging professional associations such as the Society for Human Resource Management (Bezzina et al., 2017; Rynes et al., 2002).

However, distribution of practitioner-friendly research evidence alone may be insufficient to change beliefs and attitudes. A randomized controlled trial found that participants were less likely to accept research evidence they perceived as threatening to their self-concepts (Caprar et al., 2016). A meta-analysis further uncovered that those who developed arguments upholding misinformation were less likely to change their beliefs (Chan et al., 2017). Alternatively, providing new information to update misinformation and fostering a culture conducive to scrutiny and critical thinking facilitated the acceptance of new evidence (Chan et al., 2017). Promoting this type of questioning culture included providing examples and demonstrations of the face validity of evidence and stressing the falsifiable nature of science (Caprar et al., 2016; HakemZadeh \& Baba, 2016; Shollo et al., 2015)

\section{Recommendations}

Conceptualizing research evidence utilization as an innovation, this review suggests that the organizational culture factors of beliefs, values, and practices moderates the influence of innovation diffusion efforts on behavioral factors which lead to the uptake of research evidence by management practitioners.
Change is unlikely when management practitioners are simply supplied with evidence-based research. To be effective, the research must either be aligned with or compelling enough to change the practitioner's beliefs, values, and practices. Managers wishing to promote research evidence adoption should consider strategies that are leader-driven, provide a relative advantage, are compatible with organizational culture, are highly visible, can be easily experimented with, and are not complex.

Based on this synthesis, eight recommendations emerged for practitioners to facilitate research evidence adoption (see Table 3). Furthermore, the synthesis revealed three additional recommendations for scholars to facilitate the adoption of research evidence by practitioners (see Table 4). Together, these recommendations can foster an environment in which research evidence utilization becomes a norm for practice, is valued within organizations, and is believed by practitioners to yield beneficial results.

\section{Conclusions}

The purpose of this systematic review was to explore how organizational culture influences the adoption of research evidence by management practitioners. The theories of innovation diffusion (Rogers, 1995) and planned behavior (Ajzen, 1991) were integrated to develop a model suggesting how organizational culture factors serve as moderators between innovation diffusion efforts and behavioral factors, leading to research evidence adoption. Employing a framework synthesis, we developed an emergent framework that reveals existing levels of evidence for the relationships between the innovation diffusion, organizational culture, and planned behavior constructs. 
This systematic review produced evidence that beliefs, values, and practices function as organizational culture constructs that moderate the effect of innovation diffusion constructs (i.e., compatibility, complexity, observability, relative advantage, trialability) on planned behavior constructs (i.e., attitude, behavior control, subjective norms) for the adoption of research evidence by management practitioners. While strong and moderate levels of evidence were found for the relationships between certain factors, minor levels of evidence were found for the relationships between many of the factors in the model (see Figure 2). Thus, there are gaps in the existing literature regarding the relationships presented in this model that should be explored by future primary research. While additional research is needed to further develop the model presented in this review, this is the first known systematic review to synthesizes empirical evidence on how beliefs, values, and practices influence research evidence adoption. It also proposes a new theoretical framework to explain research evidence adoption.

This study had limitations that could also benefit from future research. First, while the article search, critical appraisal, and selection was systematically conducted and documented, the interpretation of the analysis is subject to researcher bias. Other researchers could have uncovered additional evidence or applied a different theoretical framework. Second, the coding analysis uncovered evidence of relatedness between the constructs but fell short of establishing any true correlation. Due to the emergent nature of the proposed framework, future cross-sectional studies are necessary to establish the suggested correlations. Furthermore, we assumed a linear relationship between the innovation diffusion, cultural, and behavioral constructs in the framework. However, cause-and-effect studies are needed to determine the true direction of causality. Nevertheless, this study proposes actionable recommendations to facilitate the use of research evidence by management practitioners, and researchers are invited to improve upon the proposed model.

\section{References}

References with an asterisk $\left(^{*}\right)$ were used in the systematic review

Ajzen, I. (1991). The theory of planned behavior. Organizational Behavior and Human Decision Processes, 50(2), 179-211. https://doi. org/10.1016/0749-5978(91)90020-T

Barends, E., \& Rousseau, D. M. (2018). Evidence-based management: How to use evidence to make better organizational decisions. Kogan Page.

Barends, E., ten Have, S., \& Huisman, F. (2012). Learning from other evidence-based practices: The case of medicine. In D. M. Rouseau (Ed.), The Oxford Handbook of Evidence-Based Management (pp. 25-57). Oxford University Press. https://doi. org/10.1093/oxfordhb/9780199763986.013.0002

*Barends, E., Villanueva, J., Rousseau, D. M., Briner, R. B., Jepsen, D. M., Houghton, E., \& Ten Have, S. (2017). Managerial attitudes and perceived barriers regarding evidence-based practice: An international survey. PLOS ONE, 12(10), Article e0184594. https://doi.org/10.1371/journal. pone. 0184594

*Bezzina, F., Cassar, V., Tracz-Krupa, K., Przytuła, S., \& Tipuric, D. (2017). Evidence-based human resource management practices in three EU developing member states: Can managers tell truth from fallacy? European Management Journal, 35(5), 688-700. https://doi.org/10.1016/j. emj.2017.02.010

*Brown, C., \& Zhang, D. (2016). Un-rational behaviour? What causes discrepancies between teachers' attitudes towards evidence use and actual instances of evidence use in schools? Journal of Educational Administration, 54(4), 469-491. https://doi.org/10.1108/JEA-04-2015-0033

Buckley, M. R., Baur, J. E., Hardy, J. H., Johnson, J. F., Johnson, G., MaCdougall, A. E., Banford, C. G., Bagdasarov, Z., Peterson, D. R., \& Peacock, J. (2015). Management lore continues alive and well in the organizational sciences. Journal of Management History, 21(1), 68-97. https://doi. org/10.1108/JMH-05-2013-0027

${ }^{*}$ Caprar, D. V., Do, B., Rynes, S. L., \& Bartunek, J. M. (2016). It's personal: An exploration of students' (non) acceptance of management research. Academy of Management Learning and Education, 15(2), 207-231. https://doi.org/10.5465/ amle.2014.0193

Center for Evidence-Based Management. (n.d.). Articles on evidence-based management. https:// www.cebma.org/articles/

Center for Evidence-Based Management. (n.d.). CEBMa's online course modules. https://cebma. org/resources-and-tools/course-modules/

${ }^{*}$ Chan, M. pui S., Jones, C. R., Hall Jamieson, K., \& Albarracín, D. (2017). Debunking: A meta-analysis of the psychological efficacy of messages countering misinformation. Psychological Science, 28(11), 1531-1546. https://doi. org/10.1177/0956797617714579

Commission on Evidence-Based Policymaking. (2017). The promise of evidence-based

policymaking: Report of the Commission on Evidence-Based Policymaking. https://www.cep.gov/ report/cep-final-report.pdf 
Cook, S. N., \& Brown, J. S. (1999). Bridging epistemologies: The generative dance between organizational knowledge and organizational knowing. Organization Science, 10(4), 382-400. https://doi. org/10.1287/orsc.10.4.381

${ }^{*}$ Criado-Perez, C., Collins, C. G., Jackson, C. J., Oldfield, P., Pollard, B., \& Sanders, K. (2020). Beyond an 'informed opinion': Evidence-based practice in the built environment. Architectural Engineering and Design Management, 16(1), 23-40. https:// doi.org/10.1080/17452007.2019.1617670

${ }^{*}$ Dalheim, A., Harthug, S., Nilsen, R. M., \& Nortvedt, M. W. (2012). Factors influencing the development of evidence-based practice among nurses: A self-report survey. BMC Health Services Research, 12(367). https://doi.org/10.1186/14726963-12-367

*Flodgren, G., O’Brien, M. A., Parmelli, E., \& Grimshaw, J. M. (2019). Local opinion leaders: Effects on professional practice and healthcare outcomes. Cochrane Database of Systematic Reviews, 6, Article CD000125. https://doi.org/10.1002/14651858. CD000125

${ }^{\star}$ Francis-Smythe, J., Robinson, L., \& Ross, C. (2013). The role of evidence in general managers' decision-making. Journal of General Management, 38(4), 3-21. https://doi. org $/ 10.1177 / 030630701303800402$

Giluk, T. L., \& Rynes-Weller, S. L. (2012). Research findings practitioners resist: Lessons for management academics from evidence-based medicine. In D. M. Rousseau (Ed.), The Oxford handbook of evidence-based management (pp. 130-164). Oxford University Press.

${ }^{*}$ Glaub, M. E., Frese, M., Fischer, S., \& Hoppe, M. (2014). Increasing personal initiative in small business managers or owners leads to entrepreneurial success: A theory-based controlled randomized field intervention for evidence-based management. Academy of Management Learning and Education, 13(3), 354-379. https://doi. org/10.5465/amle.2013.0234

Gough, D., Oliver, S., \& Thomas, J. (2017). An introduction to systematic reviews (2nd ed.). Sage.

${ }^{*}$ Gray, M., Joy, E., Plath, D., \& Webb, S. A. (2013). Implementing evidence-based practice: A review of the empirical research literature. Research on Social Work Practice, 23(2), 157-166. https://doi. org/10.1177/1049731512467072

${ }^{*}$ HakemZadeh, F., \& Baba, V. V. (2016). Measuring the actionability of evidence for evidence-based management. Management Decision, 54(5), 1183-1204. https://doi.org/10.1108/MD-012015-0001
*Jacobs, J. A., Clayton, P. F., Dove, C., Funchess, T., Jones, E., Perveen, G., Skidmore, B., Sutton, V., Worthington, S., Baker, E. A., Deshpande, A. D., \& Brownson, R. C. (2012). A survey tool for measuring evidence-based decision making capacity in public health agencies. BMC Health Services Research, 12(1), 57. https://doi.org/10.1186/14726963-12-57

${ }^{\star} J e p s e n$, D. M., \& Rousseau, D. M. (2019, May 29June 1). How managerial evidence use relates to employee perceptions of leadership [Paper presentation]. 19th European Association of Work and Organizational Psychology Congress, Turin, Italy.

${ }^{*}$ Kalyal, H. (2019). "Well, there's a more scientific way to do it!": factors influencing receptivity to evidence-based practices in police organizations. Police Practice and Research, 21(6), 609-623. https://doi.org/10.1080/15614263.2019.1608548

Krebs, C. J. (2014). Ecological methodology (3rd ed.). https://www.zoology.ubc.ca/ krebs/books. html

March, J. G. (1994). Primer on decision making: How decisions happen. Simon and Schuster.

${ }^{*}$ McCaughan, D., Thompson, C., Cullum, N., Sheldon, T. A., \& Thompson, D. R. (2002). Acute care nurses' perceptions of barriers to using research information in clinical decision-making. Journal of Advanced Nursing, 39(1), 46-58. https://doi. org/10.1046/j.1365-2648.2002.02241.x

*Murphy, K. A., Guisard, Y., Curtin, M., Thomas, C. J., Crawford, R. E., \& Biles, J. (2018). Impact of the learning context on undergraduate students' evidence-based practice confidence and attitudes. Health Education in Practice, 1(1), 32-50. https:// openjournals.library.sydney.edu.au/index.php/ HEP/article/view/12509

Pfeffer, J., \& Sutton, R. I. (2006). Hard facts, dangerous half-truths and total nonsense: Profiting from evidence-based management. Harvard Business Review Press.

Potworowski, G. A., \& Green, L. A. (2012). Culture and evidence-based management. In D. M.

Rousseau (Ed.), The Oxford handbook of evidence-based management (pp. 272-292). Oxford University Press.

Reay, T., Berta, W., \& Kohn, M. K. (2009). What's the evidence on evidence-based management? Academy of Management Perspectives, 23(4), 5-18.

Rogers, E. M. (1995). Diffusion of innovations (4th ed.). Free Press.

Rousseau, D. M., \& Gunia, B. C. (2016). Evidence-based practice: The psychology of EBP implementation. Annual Review of Psychol- 
ogy, 67, 667-692. https://doi.org/10.1146/annurev-psych-122414-033336

${ }^{*}$ Rynes, S. L., Colbert, A. E., \& Brown, K. G. (2002). HR professionals' beliefs about effective human resource practices: Correspondence between research and practice. Human Resource Management, 41(2), 149-174. https://doi.org/10.1002/ hrm. 10029

*Shollo, A., Constantiou, I., \& Kreiner, K. (2015). The interplay between evidence and judgment in the IT project prioritization process. Journal of Strategic Information Systems, 24(3), 171-188. https://doi.org/10.1016/j.jsis.2015.06.001

*Sosnowy, C. D., Weiss, L. J., Maylahn, C. M., Pirani, S. J., \& Katagiri, N. J. (2013). Factors affecting evidence-based decision making in local health departments. American Journal of Preventive Medicine, 45(6), 763-768. https://doi.org/10.1016/j. amepre.2013.08.004

Speicher-Bocija, J., \& Adams, R. (2012). Designing strategies for the implementation of EBMgt among senior management, middle management, and supervisors. In D. M. Rousseau (Ed.), The Oxford Handbook of Evidence-Based Management (pp. 293-308). Oxford University Press.

Stols, G., \& Kriek, J. (2011). Why don't all maths teachers use dynamic geometry software in their classrooms? Australasian Journal of Educational Technology, 27(1), 137-151. https://doi. org/10.14742/ajet.988
*Tenhiala, A., Giluk, T. L., Kepes, S., Simon, C., Oh, I. S., \& Kim, S. (2016). The research-practice gap in human resource management: A cross-cultural study. Human Resource Management, 55(2), 179-200. https://doi.org/10.1002/hrm.21656

Tan, P. N., Steinbach, M., \& Kumar, V. (2005). Introduction to data mining. Pearson.

Tucker, S. (2014). Determining the return on investment for evidence-based practice: An essential

skill for all clinicians. Worldviews on Evidence-Based Nursing, 11(5), 271-273. https://doi.org/10.1111/ wvn. 12055

*Yousefi-Nooraie, R., Dobbins, M., Brouwers, M., \& Wakefield, P. (2012). Information seeking for making evidence-informed decisions: A social network analysis on the staff of a public health department in Canada. BMC Health Services Research, 12(1), 1. https://doi.org/10.1186/14726963-12-118

\section{Review}

This article was accepted under the constructive peer review option. For futher details, see the descriptions at:

http://mumabusinessreview.org/peer-review-options/

\section{Authors}

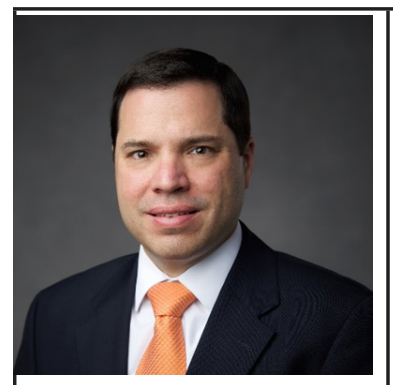

Juan Carlos Cruz is a foreign service officer for the U.S. Department of Commerce where he promotes U.S. exports, foreign investment into the United States, and international trade diplomacy. He has previous experience as a consular officer for the U.S. State Department, as a U.S. Air Force officer, and as manager of an international humanitarian organization. Juan has a Doctor of Business Administration (DBA) from University of Maryland Global Campus. He is a fellow at the Center for Evidence-Based Management.

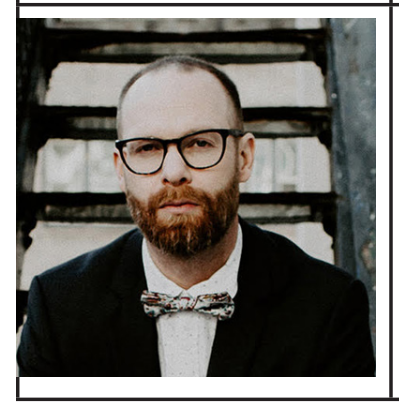

Justin Blaney, D.M., is the bestselling author of fifteen books including his most recent, Will Post for Profit: How Brands and Influencers Are Cashing In on Social Media. He is followed by more than one million on Facebook, Twitter, and Instagram @justinblaney. He publishes an app that features his writing, which can be found at www.blaney.app. Justin teaches at the University of Washington and lives in Capitol Hill, Seattle. 